\title{
DÜBLIN
}

Technological University Dublin

ARROW@TU Dublin

\section{Evaluation of Ultrasound Assisted Potassium Permanganate Pre- Treatment of Spent Coffee Waste}

\author{
Rajeev Ravindran \\ Technological University Dublin \\ Swarna Jaiswal \\ Technological University Dublin, swarna.jaiswal@tudublin.ie \\ Nissreen Abu-Ghannam \\ Technological University Dublin, nissreen.abughannam@tudublin.ie
}

See next page for additional authors

Follow this and additional works at: https://arrow.tudublin.ie/schfsehart

Part of the Bioresource and Agricultural Engineering Commons, and the Chemical Engineering Commons

\section{Recommended Citation}

Ravindran, R., Jaiswal, S., Abu-Ghannam, N. \& Jaiswal, A. K. (2016). Evaluation of ultrasound assisted potassium permanganate pre-treatment of spent coffee waste. Bioresource Technology, doi:10.1016/ j.biortech.2016.11.034

This Article is brought to you for free and open access by the School of Food Science and Environmental Health at ARROW@TU Dublin. It has been accepted for inclusion in Articles by an authorized administrator of ARROW@TU Dublin. For more information, please contact arrow.admin@tudublin.ie, aisling.coyne@tudublin.ie, gerard.connolly@tudublin.ie.

Funder: Technological University Dublin (DIT) under the

Fiosraigh Scholarship programme, 2014

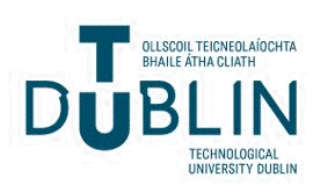




\section{Authors}

Rajeev Ravindran, Swarna Jaiswal, Nissreen Abu-Ghannam, and Amit Jaiswal 


\section{Accepted Manuscript}

Evaluation of ultrasound assisted potassium permanganate pre-treatment of spent coffee waste

Rajeev Ravindran, Swarna Jaiswal, Nissreen Abu-Ghannam, Amit K. Jaiswal

PII:

S0960-8524(16)31539-5

DOI: http://dx.doi.org/10.1016/j.biortech.2016.11.034

Reference: BITE 17280

To appear in:

Bioresource Technology

Received Date: $\quad 1$ October 2016

Revised Date: $\quad 6$ November 2016

Accepted Date: $\quad 7$ November 2016

Please cite this article as: Ravindran, R., Jaiswal, S., Abu-Ghannam, N., Jaiswal, A.K., Evaluation of ultrasound assisted potassium permanganate pre-treatment of spent coffee waste, Bioresource Technology (2016), doi: http:// dx.doi.org/10.1016/j.biortech.2016.11.034

This is a PDF file of an unedited manuscript that has been accepted for publication. As a service to our customers we are providing this early version of the manuscript. The manuscript will undergo copyediting, typesetting, and review of the resulting proof before it is published in its final form. Please note that during the production process errors may be discovered which could affect the content, and all legal disclaimers that apply to the journal pertain. 
Evaluation of ultrasound assisted potassium permanganate pre-treatment of spent coffee waste

Rajeev Ravindran ${ }^{1}$, Swarna Jaiswal ${ }^{2}$, Nissreen Abu-Ghannam ${ }^{1}$, Amit K. Jaiswal ${ }^{1}$ *

${ }^{1}$ School of Food Science and Environmental Health, College of Sciences and Health, Dublin

Institute of Technology, Cathal Brugha Street, Dublin 1, Republic of Ireland.

${ }^{2}$ Centre for Research in Engineering and Surface Technology, FOCAS Institute, Dublin

Institute of Technology, Kevin Street, Dublin 8, Republic of Ireland.

*Corresponding author:

Email: amit.jaiswal@dit.ie; akjaiswal@outlook.com

Tel: +353 14024547

\section{Abstract}


In the present study, novel pre-treatment for spent coffee waste (SCW) has been proposed which utilises the superior oxidising capacity of alkaline $\mathrm{KMnO}_{4}$ assisted by ultra-sonication . The pre-treatment was conducted for different exposure times (10, 20, 30 and $40 \mathrm{~min})$ using different concentrations of $\mathrm{KMnO}_{4}(1,2,3,4,5 \% \mathrm{w} / \mathrm{v})$ at room temperature with solid/liquid ratio of 1:10. Pretreating SCW with $4 \% \mathrm{KMnO}_{4}$ and exposing it to ultrasound for 20 min resulted in $98 \%$ cellulose recovery and a maximum lignin removal of $46 \% .1 .7$ fold increase in reducing sugar yield was obtained after enzymatic hydrolysis of $\mathrm{KMnO}_{4}$ pretreated $\mathrm{SCW}$ as compared to raw. SEM, XRD and FTIR analysis of the pretreated SCW revealed the various effects of pretreatment. Thermal behaviour of the pretreated substrate against the native biomass was also studied using DSC. Ultrasound-assisted potassium permanganate oxidation was found to be an effective pretreatment for SCW, and can be a used as a potential feedstock pretreatment strategy for bioethanol production.

Keywords: Lignocellulose; biomass pretreatment; alkaline potassium permanganate; spent coffee waste; ultrasonication; reducing sugar.

\section{Introduction}

The world had been heavily dependent on fossil fuels to meet its energy needs. Depleting fossil fuel reserves and global warming has urged man to look for feasible, eco-friendly alternatives for sustainable energy. The production of second-generation fuels from lignocellulose has shown lot of promise during the past many decades. Lignocellulosic 
ethanol has been tagged as a replacement for liquid fossil fuels. Many countries such as Brazil and Australia has adopted the practice of blending ethanol with petrol to run cars. Lignocellulose is the most abundant renewable resource in the world. Most plant material are lignocellulosic in nature and is mainly composed of three components viz. cellulose, hemicellulose and lignin. One of the main concerns of converting lignocellulose into biofuels is logistics. Luckily, wastes emerging from the food processing industry can be systematically collected and processed as it also happens to be a part of the food supply chain. These wastes can then be hydrolysed chemically or enzymatically to release metabolizable sugars such as glucose and xylose. Microorganisms utilise these sugars for sustenance as well as the production of commercially important products such as biofuels, enzymes, and amino acids.

A lignocellulose biorefinery unit essentially consists of three processes: pretreatment, enzymatic hydrolysis and fermentation. Pretreatment is an important step in lignocellulosic utilisation because plant biomass is in itself very recalcitrant in nature. This can lead to very low yields during enzymatic conversion of lignocellulose into fermentable sugars. Pretreatment strategies utilise physical, chemical, biological or a combination of these methods to structurally breakdown lignocellulose with or without lignin removal to expose cellulose and hemicellulose for hydrolysis. Furthermore, it influences the overall cost of production by decreasing detoxification, enzyme loading, and other variables. The major factors that govern enzymatic saccharification of lignocellulose are chemical composition of the biomass (especially lignin content), crystallinity of cellulose, available surface area and the presence of acetyl groups (Ravindran \& Jaiswal, 2016). An efficient pretreatment strategy should maximise the efficacy of enzymatic saccharification while minimising the formation of inhibitors along with effluent generation while operating in low energy demand, capital and operational costs (Raghavi et al., 2016). 
Spent coffee waste (SCW) is the solid material obtained after brewing of instant coffee. It is rich source of lignocellulose. Over the past few years' global coffee production and consumption has been on the rise. It is estimated that the global coffee production in $2015 / 16$ amounted up to 8,604 million tonnes (ICO, 2016). Several pretreatment methods have been devised for lignocellulose over the past decade. Dilute acid hydrolysis, steam explosion, dilute alkali assisted microwave treatment, ammonia fibre explosion, wet oxidation, and conc. phosphoric acid-acetone pretreatment are some of the most popular and effect pretreatment strategies for lignocellulose. However, very few studies have been reported on pretreatment of spent coffee waste. Kwon et al. (2013) conducted a study based on SCW by subjecting it to dilute acid pretreatment and subsequent conversion to ethanol. Characterisation of polysaccharides extracted from alkali pretreated SCW was performed by Ballesteros et al. (2015). Hydrothermal pretreatment was selected as the pretreatment strategy by Conde and Mussatto (2015) for the isolation of polyphenols from SCW. Similarly, Scully et al. (2016) investigated spent coffee waste as a renewable source of bioactive compounds and industrially important sugars and considered hydrothermal pretreatment before subjecting to enzymatic saccharification process.

Ultrasonication pretreatment is a novel and effective pretreatment method for lignocellulose (Velmurugan \& Muthukumar, 2012a). In an aqueous environment ultrasound waves induce cavitation which in bubbles form tend to collapse and expand with ultrasound waves until they collapse. This leads to the generation of heat with localised temperatures reaching $5000 \mathrm{~K}$ and pressures of $1000 \mathrm{~atm}$. The collapse also leads to the formation of reactive radical species $\left(\mathrm{H}, \mathrm{OH}, \mathrm{HO}_{2}, \mathrm{O}_{3}\right.$ etc.). Ultrasonic reactors can be of probe (horn) type or water bath type. Water bath sonicators are mild in nature compared to probe sonicators (Bussemaker \& Zhang, 2013). In a recently published study by Liyakathali et al. (2016) evaluated the effect of frequency and reaction time required for pretreating cane bagasse using ultrasound for 
bioethanol production. Correspondingly, permanganate oxidation is an effective method in lignin degradation (Bose et al., 1998). Potassium permanganate is inexpensive and potentially less toxic compared to acids and alkalis. It has been widely used for water purification. Although a pretreatment strategy employing potassium permanganate will lead to effluents consisting of the oxidizing agent it will gradually precipitate by generating manganese oxide rendering no harm to the environment (Ma et al., 2015).

In the present study, an attempt was made to combine the effects of ultrasound and potassium permanganate oxidation by using a water bath ultrasonic reactor. The optimum potassium permanganate concentration and reaction time were analysed to obtain high cellulose and hemicellulose recovery while achieving maximum lignin removal. Characterisation of the hydrolysate, physical characteristics, crystallinity and structure of the pretreated SCW was analysed by high performance liquid chromatography (HPLC), Field emission scanning electron microscopy (FE-SEM), X-ray diffraction (XRD) and Fourier transform infrared spectroscopy (FTIR) respectively. Furthermore, the thermal behaviour of native as well as pretreated SCW was studies by performing differential scanning calorimetry (DSC).

\section{Methods}

\subsection{Materials and reagents}

Spent Coffee Waste (SCW) was collected from a local coffee outlet in Dublin City, Ireland. The collected SCW was weighed, dried at $80^{\circ} \mathrm{C}$ for $48 \mathrm{~h}$ after which it was packed and stored at room temperature until further use (Kwon et al., 2013). All the chemicals such as sodium hydroxide, potassium permanganate, cellulase from Trichoderma reesei ATCC 26921, hemicellulose Aspergillus niger and xylan from beech wood were purchased from SigmaAldrich, Ireland. Cellulase enzyme registered an activity of 77 FPU/mL (Filter Paper Unit activity) while hemicellulase exhibited $72 \mathrm{U} / \mathrm{mL}$ enzyme activity. Cellulase activity was 
assayed following laboratory analytical procedure for the measurement of cellulase activities, National Renewable Energy Laboratory (Adney \& Baker, 1996). Meanwhile, hemicellulase activity was measured following enzymatic activity assay provided by Rickard and Laughlin (1980).

\subsection{Pretreatment of SCW}

\subsubsection{Ultrasound-assisted potassium permanganate pre-treatment}

Dry SCW was dispersed in potassium permanganate solution in conical flasks with a biomass loading of $10 \% \mathrm{w} / \mathrm{v}$ (solid to liquid ratio of 1:10). The reaction times were maintained for 10 , 20, 30 and 40 min respectively. The effect of different potassium permanganate solutions ( $\mathrm{pH}$ 11.5-12) were also studied ranging from $1 \%, 2 \%, 3 \%, 4 \%$ and $5 \%$. The samples were subjected to ultrasound radiation in an ultrasonic bath at frequency of $47 \mathrm{kHz}$ and an emission power of 310W (ULTRAsonik ${ }^{\mathrm{TM}} 57 \mathrm{X}$, Ney Dental Inc., USA). All the experiments were performed at room temperature. The pre-treated residues were washed with distilled water, filtered and then dried at $80^{\circ} \mathrm{C}$ until constant weight was attained. The dried residues were subjected to compositional analysis to determine the optimal conditions for pretreatment using two step sequential acid hydrolysis (Sluiter et al., 2008). All the tests were done in triplicates.

\subsubsection{Alkali assisted Ultrasonication}

For comparative studies, $1 \mathrm{~g}$ of SCW was taken in a $100 \mathrm{~mL}$ conical flask and was suspended in $10 \mathrm{~mL}$ of $\mathrm{NaOH}$ in $1.0,2.0,3.0,4.0$ and $5.0 \%$ concentration $(\mathrm{w} / \mathrm{v})$. The contents were mixed well and sonicated for $30 \mathrm{~min}$ at $25 \mathrm{KHz}$ frequency with an effective ultrasonic power of $150 \mathrm{~W}$ using an ultrasonicator (ULTRAsonik ${ }^{\mathrm{TM}}$ 57X, Ney Dental Inc., USA). The resultant liquid after ultrasonication was analysed for reducing sugar, hydroxymethyl furfural 
(HMF) and furfural. The residue after repeated washings with deionized water was dried in an oven at $50^{\circ} \mathrm{C}$ for $48 \mathrm{~h}$ and analysed for different components (Gabhane et al., 2014).

\subsection{Enzymatic hydrolysis}

Response Surface Methodology (RSM) was applied to statistically optimise the reaction conditions for enzymatic hydrolysis of SCW to evaluate the main effects, interaction effects and quadratic effects of five factors (biomass loading, enzyme loading (cellulase and hemicellulase) $\mathrm{pH}$ and time). A Central Composite Design (CCD) with five factors and five levels including five replicating centre point was created using STATGRAPHICS Centurion XV software (StatPoint Technologies Inc. Warrenton, VA, USA) (Table 1). In order to find the optimum conditions, following parameters were considered: biomass loading, cellulase (77.08 FPU/mL) and hemicellulase $(72.23 \mathrm{U} / \mathrm{mL})$ loading, incubation time and $\mathrm{pH}$ were selected as presented in Table 1. To optimise the enzymatic reaction, appropriate amount of SCW, celluase, hemicellulase and $0.5 \%$ sodium azide was mixed in sodium citrate buffer of designated $\mathrm{pH}$ to achieve the required reaction mixture. The reaction volume was maintained at $50 \mathrm{~mL}$ and the temperature was set at $50^{\circ} \mathrm{C}$. The reaction mixture was incubated for respective time period given by software $(24,48,72,96$ and $120 \mathrm{~h}$ ) (Table 1$)$. On completion of the experiments the suspensions were transferred to $30 \mathrm{~mL}$ polypropylene tubes, centrifuged at $7000 \mathrm{rpm}$ for $10 \mathrm{~min}$. The supernatant was collected and stored at $-20^{\circ} \mathrm{C}$ for further analysis.

\subsection{Compositional analysis}

Raw and pretreated SCW were subjected to compositional analysis by following two-stage acid hydrolysis according to The National Renewable Energy Laboratory (NREL) protocol (Sluiter et al., 2005). The reducing sugar concentration in the hydrolysate was estimated by dinitro salicylic acid (DNS) method (Miller, 1959). The presence and quantification of 
monosaccharides, organic acids and any inhibitors in the form of furfural and hydroxymethylfurfural was done on an Alliance HPLC (Waters, e2695 Separation module) using a Rezex ROA-Organic acid H+ (8\%) column, (350 x 7.8 mm; Phenomenex, UK) with $5 \mathrm{mM} \mathrm{H}_{2} \mathrm{SO}_{4}$ as the mobile phase at $65^{\circ} \mathrm{C}$ maintaining a flow rate of $0.6 \mathrm{~mL} / \mathrm{min}$ (Jaiswal et al., 2012).

The percentage recovery and percentage removal were calculated using the following formula:

$$
\begin{gathered}
\% \text { recovery }=\mathrm{W}_{\text {pre }} / \mathrm{W}_{\text {raw }} \times 100 \\
\% \text { removal }=1-\% \text { recovery }
\end{gathered}
$$

where, $\mathrm{W}_{\text {pre }}$ and $\mathrm{W}_{\text {raw }}$ are the weight of the corresponding component (cellulose, hemicellulose and lignin) in pre-treated and raw SCW (g) respectively (Ma et al., 2015).

\subsection{Characterization of raw and pre-treated substrate}

\subsubsection{Scanning electron microscopy}

The morphological structure of spent coffee waste and the effect of pretreatment on the same were observed by performing FE-SEM. Dried samples of the untreated and pretreated SCW were subject to FE-SEM. FE-SEM analysis was completed using a Hitachi SU-70 Field emission microscope operating at electron beam energy of $0.5 \mathrm{keV}$ (Raghavi et al., 2016).

\subsubsection{X-ray diffraction}

The crystalline phases in untreated coffee waste and its pretreated counterpart were analysed using X-ray diffraction. Siemens D-500 X-ray diffractometer was used for this purpose with diffraction angles spanned from $2 \theta=5^{\circ}-50^{\circ}$ using a $\mathrm{Cu} \mathrm{K} \alpha$ radiation source $(\lambda=0.154 \mathrm{~nm})$. The radiation was generated at a voltage of $40 \mathrm{kV}$ and current of $30 \mathrm{~mA}$ (Binod et al., 2012). 


\subsubsection{FTIR analysis}

FTIR spectroscopy was performed to identify the changes in the functional groups in the SCW before and after pretreatment employing Perkin Elmer Spectrum GX FT-IR (UATR) Microscope (USA). The FTIR spectrum was recorded from 4000 to $400 \mathrm{~cm}^{-1}$ with 16 scans at a resolution of $0.3 \mathrm{~cm}^{-1}$ in transmission mode (Raghavi et al., 2016).

\subsubsection{Thermal behaviour}

The thermal behaviour of the treated and raw samples were studied and compared using differential scanning calorimetry (DSC). The equipment, Shimadzu DSC-60 was operated using TA-60WS software. For analysis, $55 \mathrm{mg}$ of sample was places in an aluminium pan and an empty pan was used as a reference. The measurements were carried out between $25^{\circ} \mathrm{C}$ and $500^{\circ} \mathrm{C}$ with a linear increase of $10^{\circ} \mathrm{C} /$ minute (Ballesteros et al., 2015).

\subsection{Statistical analysis}

Experiments were carried out in triplicates. Significant differences were computed by employing analysis of variance (ANOVA) and multiple comparisons (Fischer's least significant difference test) by employing STATGRAPHICS Centurion XV software (StatPoint Technologies Inc. Warrenton, VA, USA). Value of $p<0.05$ was considered as significant value.

\section{Results and discussion}

\subsection{Effect of pre-treatment on composition of spent coffee waste}

\subsubsection{Effect of pretreatment conditions on biomass}

The compositional analysis of native SCW revealed the presence of four major reducing sugars viz. glucose, mannose, arabinose and galactose. This indicated that SCW is rich in glucomannan, arabinogalactan and cellulose structures. SCW was abundant in hemicellulose content $(33.5 \mathrm{~g} / 100 \mathrm{~g}$ of dry SCW) as compared to cellulose $(8.6 \mathrm{~g} / 100 \mathrm{~g}$ of dry SCW). The 
total lignin content amounted to $31.1 \mathrm{~g} / 100 \mathrm{~g}$ of dry SCW. The primary objective behind this study was to achieve maximum lignin removal along with maximum cellulose and hemicellulose recovery. This is because lignin removal will improve the degree of enzymatic hydrolysis of lignocellulosic biomass. The lignin removal strategies in this pretreatment process viz. potassium permanganate concentration and ultrasonication time were optimised based on cellulose and hemicellulose recovery coupled with lignin removal. The effect of potassium permanganate concentration on the recovery of lignin and polysaccharides have been illustrated in Fig 1. Potassium permanganate reacts with lignin to form carboxylic methyl esters. Lignin is more susceptible to oxidation by potassium permanganate compared to the polysaccharide fraction of lignocellulose. Potassium permanganate concentration is directly linked to oxidation capacity and plays an important role in delignification (Gellerstedt, 1992). The changes in the recovery of cellulose incurred was found to be significant with respect to increasing potassium permanganate concentration $(p<0.05)$. Maximum recovery of cellulose was achieved by using $4 \%(\mathrm{w} / \mathrm{v})$ potassium permanganate solution. However, lignin and hemicellulose recoveries were significantly impacted by the presence of potassium permanganate $(p<0.05)$. Lignin recovery progressively decreased from $59.2 \%$ to $46.7 \%$ with increasing concentration of potassium permanganate. Likewise, the hemicellulose recovery ( $85 \%$ to $60 \%$ ) was also detrimentally effected especially after the concentration of potassium permanganate was increased beyond $4 \%$. Higher concentrations of potassium permanganate resulted in the oxidation of more ester and ether linkages in the hemicellulose fraction. This may be due to the amorphous nature of hemicellulose making it susceptible to extensive solubilisation when the concentration of the oxidising agent was increased.

Several studies have reported ultrasonication as an effective pretreatment strategy for lignocellulosic biomass. Sonication probes are commonly used as the ultrasonication 
instrument at high frequencies (Subhedar \& Gogate, 2014). However, this study employed a sonication water bath, which is mild as compared to the probe sonicator. Nonetheless the treatment strategy did have an effect on SCW. The effect of time on pre-treated SCW is shown in Fig. 2. Cellulose recovery increased with increase in time. The same was not observed in the case of hemicellulose and lignin. The resistance of cellulose to pretreatment conditions can be attributed to its crystalline nature. Velmurugan and Muthukumar (2012b) reported high losses in cellulose and hemicellulose content in sugarcane bagasse as a result of over exposure to strong ultrasound frequencies. However, in this experiment the loss of biomass component due to prolonged exposure to ultrasound radiation was overcome since the longest treatment time only lasted $40 \mathrm{~min}$ while untilising a mild sonication instrument. The variations in exposure time had a significant impact on recovery of cellulose $(p<0.05)$. Cellulose recovery amounted up to $87.25 \%$ while that of hemicellulose and lignin was $42.42 \%$ and $35.45 \%$ respectively after 40 min of ultrasonication. Moreover, statistical analysis of the effect of exposure time on the cellulose, hemicellulose and lignin recovery revealed that there is a significant difference between the recovery of the three major components at $95 \%$ confidence interval.

The removal of lignin content can be attributed to the effect of cavitation and the oxidation of the ester and ether bonds which had a deleterious effect on the amount of soluble as well as insoluble lignin content. This phenomenon was also reported by García et al. (2012) when they studied the effect of ultrasound on the properties of alkaline lignin. In an aqueous solution ultrasound waves give rise to highly reactant species such as hydroxyl ions, hydronium ions, ozone which interact lignocellulosic components (cellulose, hemicellulose and lignin) and results in its decay. Exposing lignocellulose to longer periods of ultrasound waves resulted in extensive removal of lignin and hemicellose. Although lignin removal was at maximum after $40 \mathrm{~min}$ the optimum time for pretreatment was set at $20 \mathrm{~min}$ as there was 
no significant increment in cellulose content after $20 \mathrm{~min}$ of pretreatment. All experiments were performed at room temperature thus eliminating the requirement of any heating element and contributing to cost reduction of the overall process.

\subsection{Optimisation of enzymatic hydrolysis parameters using response surface methodology}

The aim of the optimization study was to find the optimum parameters that would maximise reducing sugar yields. Spent coffee waste has a high hemicellulose content as opposed to other lignocellulose sources. Hence it was expected that hemicellulase concentration will play a vital role in the release of sugars. Total reducing sugar after enzymatic saccharification of pretreated biomass obtained from 30 experiments are listed in Table 2. The models were compared based on the coefficient of determination $\left(\mathrm{R}^{2}\right)$ and adjusted coefficient of determination $\left(\mathrm{R}^{2}\right.$-adj). The $\mathrm{R}^{2}$ is defined as the regression of sum of squares proportion to the total sum of squares, which illustrates the adequacy of a model. $\mathrm{R}^{2}$ ranges from 0 to 1 and $\mathrm{R}^{2}$ values closer to 1 , means the model is more accurate. A value of $99.26 \% \mathrm{R}^{2}$ was observed in the present study while $\mathrm{R}^{2}$-adj was $97.62 \%$ illustrates the model adequately fits the data. The data obtained from the central composite design were fitted to second order polynomial equations. The polynomial equation for the model is given below:

Reducing sugar $(\mathrm{mg} / \mathrm{mL})=8.0815+4.0795 X_{1}-6.346 X_{2}-1.318 X_{3}+0.218 X_{4}+2.478 X_{5}-$

$$
\begin{aligned}
& 0.592 X_{1}^{2}+2.425 X_{1} X_{2}-0.870 X_{1} X_{3}-0.00515 X_{1} X_{4}+0.0270 X_{1} X_{5}+ \\
& 1.505 X_{2}^{2}+1.722 X_{2} X_{3}-0.0659 X_{2} X_{4}+0.111 X_{2} X_{5}+0.130 X_{3}^{2}+ \\
& 0.0289 X_{3} X_{4}+0.0902 X_{3} X_{5}-0.00047 X_{4}^{2}-0.0125 X_{4} X_{5}-0.179 X_{5}^{2}
\end{aligned}
$$

where $X_{1}, X_{2}, X_{3}, X_{4}$ and $X_{5}$ represents biomass loading, cellulase loading, hemicellulase loading, $\mathrm{pH}$ and incubation time, respectively. The significance of the coefficients of the models was determined by analysis of variance (ANOVA). ANOVA table showed that 13 
effects have P-values less than 0.05 , indicating that they are significantly different from zero at the $95.0 \%$ confidence level, indicating the considerable effect of these coefficients on reducing sugar yield. All the linear coefficients were found positive significant effect $(p<$ 0.05) on the maximum reducing sugar yield from pretreated SCW. However, only biomass, cellulase loading, hemicellulase loading and time showed positive significant interaction effect $(p<0.05)$ on the maximum reducing sugar yield. Among quadratic coefficients only cellulase loading had positive effect on the maximising reducing sugar yield.

Furthermore, three-dimensional response plot is plotted to understand the interactions between different variables and to determine the optimal level of each variable for maximum response. Three-dimensional response surfaces generated further gave insights on the interaction between the five factors tested (Fig. 3). The contour plots revealed that there was significant interaction between each parameter taken in this study albeit in varying degrees. The highest interactions were recorded between SCW and time (Fig. 3b) and, SCW and hemicellulase (Fig 3d). The highly significant interactions between SCW and hemicellulase can be attributed to the high hemicellulose content in the biomass. As is evident from the graphs cellulase and hemicellulase enzymes has least interaction with each other (Fig 3a). The highest point on the three-dimensional plot determines the optimal value for each parameter to attain maximum reducing sugar yield. A maximum reducing yield was observed with high biomass loading $(5 \mathrm{~g} / 50 \mathrm{~mL})$, cellulase $(1.5 \mathrm{~mL} / 50 \mathrm{~mL})$, hemicellulase $(0.37$ $\mathrm{mL} / 50 \mathrm{~mL}), \mathrm{pH}(6.7)$ and a short incubation time $(24 \mathrm{~h})$. Furthermore, the model predicted the maximum sugar yield to be $35.64 \mathrm{mg} / \mathrm{mL}$ of reaction volume. For the validation of the model a confirmation experiment was conducted using the optimised parameters. Experimentally obtained values of total reducing sugar amounted to $35.15 \pm 0.2 \mathrm{mg} / \mathrm{mL}$, which suggested that there was little disparity $(<5 \%)$ between predicted and observed values, and the model was adequate to predict the optimum parameters for saccharification of CSW. Since the time 
period for completion of the reaction was $24 \mathrm{~h}$ scale-up of this model is a feasible option (Sánchez, 2009).

\subsection{Identification and quantification of reducing sugars}

The influence of ultrasonication assisted potassium permanganate pretreatment on reducing sugar production was investigated by enzymatic hydrolysis using the reaction parameters described in the earlier section. As a comparison measure, alkali assisted ultrasonicated SCW and raw SCW was also subjected to enzymatic hydrolysis. Results for reducing sugar yield and monosaccharides are provided in Table 3. Glucose, mannose, galactose and arabinose were identified as the monosaccharides present in the hydrolysate with sparse amounts of cellobiose. The hydrolysate was marked by the absence of xylose. Studies performed by other authors have reported the presence of the same sugars in SCW hydrolysate (Kwon et al., 2013; Mussatto et al., 2011). Ultrasound assisted potassium permanganate pretreatment improved the reducing sugar yield as compared to raw and alkali assisted ultrasound pretreated SCW which was due to high cellulose recovery and lignin removal. Clearly, ultrasound pretreatment coupled with potassium permanganate was a superior pretreatment strategy compared to alkali assisted ultrasonication as can be seen from the recoveries of individual sugars. A higher concentration of insoluble lignin was found in alkali assisted ultrasonicated SCW as compared to potassium permanganate assisted ultrasonicated SCW. However, alkali assisted pretreatment was a better method in the removal of acid soluble lignin. With respect to reducing sugar yield a 1.7-fold increase in yield was observed when employing ultrasound assisted $\mathrm{KMnO}_{4}$ pretreatment $(341.2 \mathrm{mg} / \mathrm{g}$ of substrate) compared to untreated SCW (199.8.mg/g of substrate). Meanwhile, a reducing sugar release of $305.6 \mathrm{mg} / \mathrm{g}$ of substrate was obtained by subjecting alkali assisted ultrasound pretreated SCW. 


\subsection{Identification of inhibitors in hydrolysate}

The hydrolysate obtained was analysed for the presence of any inhibitors such as furfural and 5-hydroxymethyl furfural (HMF) and other organic acids such as acetic acid, lactic acid, succinic acid, propionic acid and oxalic acid. The analysis revealed the absence of any such chemicals and deemed the hydrolysate fit for fermentation purposes. Furfural and HMF are formed as a result of thermochemical treatment of lignocellulose. The absence of inhibitors can be justified by the nature of this pretreatment strategy since it was devoid of any heat or strong acids. This study was important since detoxification processes to remove inhibitors can add up to the cost of ethanol fermentation by a factor of $22 \%$ (Lau et al., 2008).

\subsection{Characterisation of pre-treated spent coffee waste}

\subsubsection{Fourier transform infrared spectroscopy}

The structural and compositional changes in the pretreated SCW was observed and measured by SEM, XRD and FTIR. FTIR spectra (shown in supporting information, Fig. S1) was different for pretreated and raw SCW which indicated differences in the structure of cellulose in both samples. The bands 875 to $930 \mathrm{~cm}^{-1}$ indicate glycosidic bonds in cellulose and hemicellulose (Sills \& Gossett, 2012). The reduction in intensity of peaks representing glycosidic bonds was observed in pretreated SCW compared to untreated SCW. This can be due to the disruption of these bonds during the pretreatment process, resulting in the release of monosaccharides. The absorbance of band at $1035 \mathrm{~cm}^{-1}$ was observed in the pretreated $\mathrm{SCW}$ sample which indicates $\mathrm{C}-\mathrm{O}, \mathrm{C}=\mathrm{C}$ and $\mathrm{C}-\mathrm{C}-\mathrm{O}$ stretching between polysaccharides and lignin decreased after pretreatment (Tamaki \& Mazza, 2011). Also, decrease in peak height at $1200 \mathrm{~cm}^{-1}$ (O-H bending in cellulose and hemicellulose) suggested the breakage of hydrogen bonds between cellulose and hemicellulose. The band $1280 \mathrm{~cm}^{-1}$ represents $\mathrm{C}-\mathrm{H}$ bending and is crucial in determining the degree of crystallinity of cellulose (Binod et al., 2012). The new pretreatment strategy was able to remove cellulose crystallinity from the SCW which is 
evident in the decrease in peak absorbance at $1280 \mathrm{~cm}^{-1}$, representing $\mathrm{C}-\mathrm{H}$ bending in crystalline cellulose. The bands at $1335 \mathrm{~cm}^{-1}$ and $1380 \mathrm{~cm}^{-1}$ represent $\mathrm{C}-\mathrm{H}$ vibrations and bending between lignin and the polysaccharide fractions. Bands $1425 \mathrm{~cm}^{-1}$ and $1465 \mathrm{~cm}^{-1}$ indicate $\mathrm{C}-\mathrm{H}$ plane deformation and $\mathrm{C}-\mathrm{H}$ deformation in lignin respectively (Xu et al., 2013). The bands $1730 \mathrm{~cm}^{-1}$ and $1750 \mathrm{~cm}^{-1}$ suggest ketone/aldehyde stretch and free ester in hemicellulose (Ruiz et al., 2013). These signals were weaker in the pretreated SCW which suggested that these bonds between lignin and polysaccharides were probably cleaved by the pretreatment step. C-H stretching in cellulose is represented by the band $2920 \mathrm{~cm}^{-1}$ and the broad peaks indicate the breakage of hydrogen bonds leading to the rupture of methyl and methylene portions.

The crystallinity of cellulose has been used for several decades to study the changes incurred in the structure post pretreatment. Cellulose crystallinity plays an important role in enzymatic digestibility. Lignocellulose structure can be divided into crystalline and amorphous regions. The crystallinity of lignocellulose is contributed largely by the cellulose fraction while hemicellulose and lignin regions contribute to the amorphous nature. The amorphous nature of hemicellulose makes it highly susceptible to enzymatic hydrolysis. Furthermore, high degrees of harshness of pretreatment result in partial or complete removal of hemicellulose.

\subsubsection{X-ray diffraction}

The XRD spectra of the native and pretreated SCW was compared to evaluate the differences in the crystallinity of the respective biomass. Untreated SCW was found to be less crystalline as compared to treated samples. A unique crystalline peak was observed in both XRD patterns which was contrasting compared to XRD spectra of other lignocellulosic materials (shown in supporting information, Fig. S2). The XRD spectra of SCW suggested the presence of higher amount of amorphous material as compared to crystalline counterparts. This can be 
justified by the studies from the compositional analysis which has been discussed in earlier sections of this paper. Earlier studies on spent coffee waste reported that crystallinity in SCW is attributed to the presence of cellulose (Ballesteros et al., 2014). The peak at the $16^{\circ}$ is an indication of the amorphous structures present in SCW (in this case, hemicellulose). There was a noticeable dip in the peak intensity in the pretreated SCW spectrum at $16^{\circ}$ which is an indication of the hemicellulose removal. A difference in peaks between the native biomass and its pretreated counterpart at $22^{\circ}$ is an indication of the effectiveness of the pretreatment, caused due to the increase in disorderliness of the structure of the biomass. Raghavi et al. (2016) in their study involving sugar cane bagasse reported a similar increase in biomass crystallinity which was imparted by the increase in cellulose content. Furthermore, an increase in crystallinity signals the removal of amorphous components such lignin and hemicellulose leaving behind the crystalline cellulose. Ballesteros et al. (2015) had reported similar results using alkali pretreatment on SCW.

\subsubsection{Differential scanning calorimetry}

Differential scanning calorimetry determines the heat effects associated with phase transitions and chemical reactions as a function of temperature. The difference in heat flow in the sample and the reference (usually an empty aluminium pan) is recorded as a function of temperature. The temperature is increased at a constant rate both in the sample and reference. Since the pressure is maintained constant, the heat flow is equivalent to enthalpy. The DSC thermogram (Fig. 4) represents the thermal characteristics of the native and the pretreated SCW between $20^{\circ} \mathrm{C}$ and $500^{\circ} \mathrm{C}$ which were obtained at a heating rate of $10^{\circ} \mathrm{C} / \mathrm{min}$. The thermogram for raw SCW exhibited an exothermic event which initiated at $20^{\circ} \mathrm{C}$ and peaked at $102.9^{\circ} \mathrm{C}$. This event can be associated with the vaporisation of water. The enthalpy associated with this process was found to be $114.99 \mathrm{~J} / \mathrm{g}$. This was succeeded by a phase transformation with a change in the heat capacity which is a characteristic of every polymer. 
The glass transition temperature was recorded at $259.2^{\circ} \mathrm{C}$. Interestingly, the pretreated SCW exhibited two events: an exothermic phase followed by an endothermic phase. The exothermic phase was observed with a peak at $94.8^{\circ} \mathrm{C}$. The enthalpy associated with this event amounted to be $79.49 \mathrm{~J} / \mathrm{g}$. In contrast with the raw SCW, a crystallisation peak was observed at $348.5^{\circ} \mathrm{C}$ with a peak at $421.81^{\circ} \mathrm{C}$ with an associated enthalpy change of 485.34 $\mathrm{J} / \mathrm{g}$. Melting events were not observed for pretreated SCW which suggests the absence of any impurities.

\subsubsection{Scanning electron microscopy}

SEM analysis of the raw and pretreated SCW revealed the changes in the physical nature imparted as a result of pretreatment. Earlier studies have shown that SCW is widely porous in nature and resembles thin sheets of saw dust (Ballesteros et al., 2014). Any size reduction in the biomass structure can be attributed to the effect of the cavitation caused by the ultrasound waves. The particles in the pretreated biomass is crumbled in nature compared to the native SCW (shown in supporting information, Fig. S3). This exposed the inner parts of the biomass leading to biomass degradability. Furthermore, this also led to the increase in enzyme access total surface area.

\section{Conclusion}

The evaluation of ultrasound assisted potassium permanganate pretreatment revealed that this method is very effective for lignin and hemicellulose removal from spent coffee waste. Significant lignin removal $(45.70 \%)$ was achieved with a $\mathrm{KMnO}_{4}$ concentration of $4 \%$ and ultrasound exposure time of $20 \mathrm{~min}$. Additionally, this process was mild enough to safeguard the polysaccharide fraction (hemicellulose in particular). A 1.7 fold increase in reducing sugar yield was obtained when pretreated SCW was subjected to enzymatic hydrolysis compared to untreated SCW. The most important feature of ultrasound assisted potassium permanganate 
treatment is that no heat was used as part of this process thus rendering this technique a simple, fast and effective pretreatment strategy.

\section{Acknowledgement}

The authors would like to acknowledge the funding from Dublin Institute of Technology (DIT) under the Fiosraigh Scholarship programme, 2014.

\section{References}

Adney, B., Baker, J. 1996. Measurement of cellulase activities. Laboratory Analytical Procedure, 6, 1996.

Ballesteros, L.F., Cerqueira, M.A., Teixeira, J.A., Mussatto, S.I. 2015. Characterization of polysaccharides extracted from spent coffee waste by alkali pretreatment. Carbohydr. Polym. 127, 347-354.

Ballesteros, L.F., Teixeira, J.A., Mussatto, S.I. 2014. Chemical, Functional, and Structural Properties of Spent Coffee Grounds and Coffee Silverskin. Food Bioproces. Technol. 7(12), 3493-3503.

Binod, P., Satyanagalakshmi, K., Sindhu, R., Janu, K.U., Sukumaran, R.K., Pandey, A. 2012. Short duration microwave assisted pretreatment enhances the enzymatic saccharification and fermentable sugar yield from sugarcane bagasse. Renew. Energ. 37(1), 109-116.

Bose, S. K., Wilson Kate, L., Francis Raymond, C., Aoyama, M. 1998. Lignin Analysis by Permanganate Oxidation. I. Native Spruce Lignin. in: Holzforschung - Int. J. Biol. Chem. Phys. Technol. Wood, 52, 297.

Bussemaker, M.J., Zhang, D. 2013. Effect of Ultrasound on Lignocellulosic Biomass as a Pretreatment for Biorefinery and Biofuel Applications. Ind. Eng. Chem. Res. 52(10), 3563-3580. 
Conde, T., Mussatto, S.I. 2015. Isolation of polyphenols from spent coffee grounds and silverskin by mild hydrothermal pretreatment. Prep. Biochem. Biotechnol. 46, 406409.

Gabhane, J., William, S., Vaidya, A., Anand, D., Wate, S. 2014. Pretreatment of garden biomass by alkali-assisted ultrasonication: effects on enzymatic hydrolysis and ultrastructural changes. J. Environ. Health Sci. Engineer. 12(1), 1-6.

García, A., Erdocia, X., González Alriols, M., Labidi, J. 2012. Effect of ultrasound treatment on the physicochemical properties of alkaline lignin. Chem. Eng. Process.: Process Intensification, 62, 150-158.

Gellerstedt, G. 1992. Chemical degradation methods: permanganate oxidation. in: Methods in Lignin Chemistry, Springer, pp. 322-333.

International Coffee Organization (ICO), 2016. The Current State of the Global Coffee Trade.

Jaiswal, A.K., Gupta, S., Abu-Ghannam, N. 2012. Optimisation of lactic acid fermentation of York cabbage for the development of potential probiotic products. Int. J. Food Sci. Technol. 47(8), 1605-1612.

Kwon, E.E., Yi, H., Jeon, Y.J. 2013. Sequential co-production of biodiesel and bioethanol with spent coffee grounds. Bioresour. Technol. 136, 475-480.

Lau, M.W., Dale, B.E., Balan, V. 2008. Ethanolic fermentation of hydrolysates from ammonia fiber expansion (AFEX) treated corn stover and distillers grain without detoxification and external nutrient supplementation. Biotechnol. Bioeng. 99(3), 529539.

Liyakathali, M. N.A., Muley, P.D., Aita, G., Boldor, D. 2016. Effect of frequency and reaction time in focused ultrasonic pretreatment of energy cane bagasse for bioethanol production. Bioresour. Technol. 200, 262-271. 
Ma, L., Cui, Y., Cai, R., Liu, X., Zhang, C., Xiao, D. 2015. Optimization and evaluation of alkaline potassium permanganate pretreatment of corncob. Bioresour. Technol. 180, 1-6.

Miller, G.L. 1959. Use of dinitrosalicylic acid reagent for determination of reducing sugar. Anal. Chem. 31(3), 426-428.

Mussatto, S.I., Carneiro, L.M., Silva, J.P.A., Roberto, I.C., Teixeira, J.A. 2011. A study on chemical constituents and sugars extraction from spent coffee grounds. Carbohydr. Polym. 83(2), 368-374.

Raghavi, S., Sindhu, R., Binod, P., Gnansounou, E., Pandey, A. 2016. Development of a novel sequential pretreatment strategy for the production of bioethanol from sugarcane trash. Bioresour. Technol. 199, 202-210.

Ravindran, R., Jaiswal, A.K. 2016. A comprehensive review on pre-treatment strategy for lignocellulosic food industry waste: Challenges and opportunities. Bioresour. Technol. 199, 92-102.

Rickard, P., Laughlin, T. 1980. Detection and assay of xylanolytic enzymes in a Cellulomonas isolate. Biotechnol. Lett. 2(8), 363-368.

Ruiz, H.A., Cerqueira, M.A., Silva, H.D., Rodríguez-Jasso, R.M., Vicente, A.A., Teixeira, J.A. 2013. Biorefinery valorization of autohydrolysis wheat straw hemicellulose to be applied in a polymer-blend film. Carbohydr. Polymer. 92(2), 2154-2162.

Sánchez, C. 2009. Lignocellulosic residues: biodegradation and bioconversion by fungi. Biotechnol. Adv. 27(2), 185-194.

Scully, D. S., Abu-Ghannam, N., Jaiswal, A. K. 2016. An investigation into spent coffee waste as a renewable source of bioactive compounds and industrially important sugars. Bioengineering, 
Sills, D.L., Gossett, J.M. 2012. Using FTIR to predict saccharification from enzymatic hydrolysis of alkali-pretreated biomasses. Biotechnol. Bioeng. 109(2), 353-362.

Sluiter, A., Hames, B., Ruiz, R., Scarlata, C., Sluiter, J., Templeton, D., Crocker, D. 2008. Determination of structural carbohydrates and lignin in biomass. Laboratory Analytical Procedure, 1617.

Sluiter, A., Ruiz, R., Scarlata, C., Sluiter, J., Templeton, D. 2005. Determination of extractives in biomass. Laboratory Analytical Procedure (LAP), 1617.

Subhedar, P.B., Gogate, P.R. 2014. Alkaline and ultrasound assisted alkaline pretreatment for intensification of delignification process from sustainable raw-material. Ultrason. Sonochem. 21(1), 216-225.

Tamaki, Y., Mazza, G. 2011. Rapid Determination of Carbohydrates, Ash, and Extractives Contents of Straw Using Attenuated Total Reflectance Fourier Transform MidInfrared Spectroscopy. J. Agric. Food Chem. 59(12), 6346-6352.

Velmurugan, R., Muthukumar, K. 2012a. Sono-assisted enzymatic saccharification of sugarcane bagasse for bioethanol production. Biochem. Eng. J. 63, 1-9.

Velmurugan, R., Muthukumar, K. 2012b. Ultrasound-assisted alkaline pretreatment of sugarcane bagasse for fermentable sugar production: Optimization through response surface methodology. Bioresour. Technol. 112, 293-299.

Xu, F., Yu, J., Tesso, T., Dowell, F., Wang, D. 2013. Qualitative and quantitative analysis of lignocellulosic biomass using infrared techniques: A mini-review. Appl. Energ. 104, 801-809. 


\section{Figures Caption}

Fig. 1. Effect of potassium permanganate concentration on the recoveries of SCW residues after pretreatment

Fig. 2. Effect of ultrasound exposure on the recoveries of SCW residues after pretreatment

Fig 3. Response surface plots representing the effect of independent variables on reducing sugar yield (3a) the effect of cellulase and hemicellulase on reducing sugar yield when the response surface is fixed at $\mathrm{SCW}=3.0 \mathrm{~g} / 50 \mathrm{~mL}$, time $=72 \mathrm{~h}$ and $\mathrm{pH}=6.0$; (3b) representing the effect of time and SCW on reducing sugar yield, when the response surface is fixed at cellulase $=0.9 \mathrm{~mL} / 50 \mathrm{~mL}$, hemicellulase $=0.9 \mathrm{mg} / 50 \mathrm{~mL}, \mathrm{pH}=6.0 ;(3 \mathrm{c})$ representing the effect of cellulase, time on reducing sugar yield, when the response surface is fixed at SCW = $3 \mathrm{~g} / 50 \mathrm{~mL}$, hemicellulase $=0.9 \mathrm{~mL} / 50 \mathrm{~mL}, \mathrm{pH}=6.0$; (3d) representing the effect of hemicellulase and SCW on reducing sugar yield, when the response surface is fixed at cellulase $=0.9(\mathrm{mg} / 50 \mathrm{~mL})$, time $=72 \mathrm{~h}, \mathrm{pH}=6.0 ;(3 \mathrm{e})$ representing the effect of $\mathrm{SCW}$ and $\mathrm{pH}$ on reducing sugar yield, when the response surface is fixed at cellulase $=0.9 \mathrm{~mL} / 50 \mathrm{~mL}$, hemicellulase $=0.9 \mathrm{~mL} / 50 \mathrm{~mL}$, time $=72 \mathrm{~h}$, and $(3 \mathrm{f})$ representing the effect of SCW and cellulase on reducing sugar yield, when the response surface is fixed at hemicellulase $=0.9$ $\mathrm{mL} / 50 \mathrm{~mL}$, time $=72 \mathrm{~h}, \mathrm{pH}=6.0$.

Fig. 4. DSC thermogram of native and pretreated SCW. 


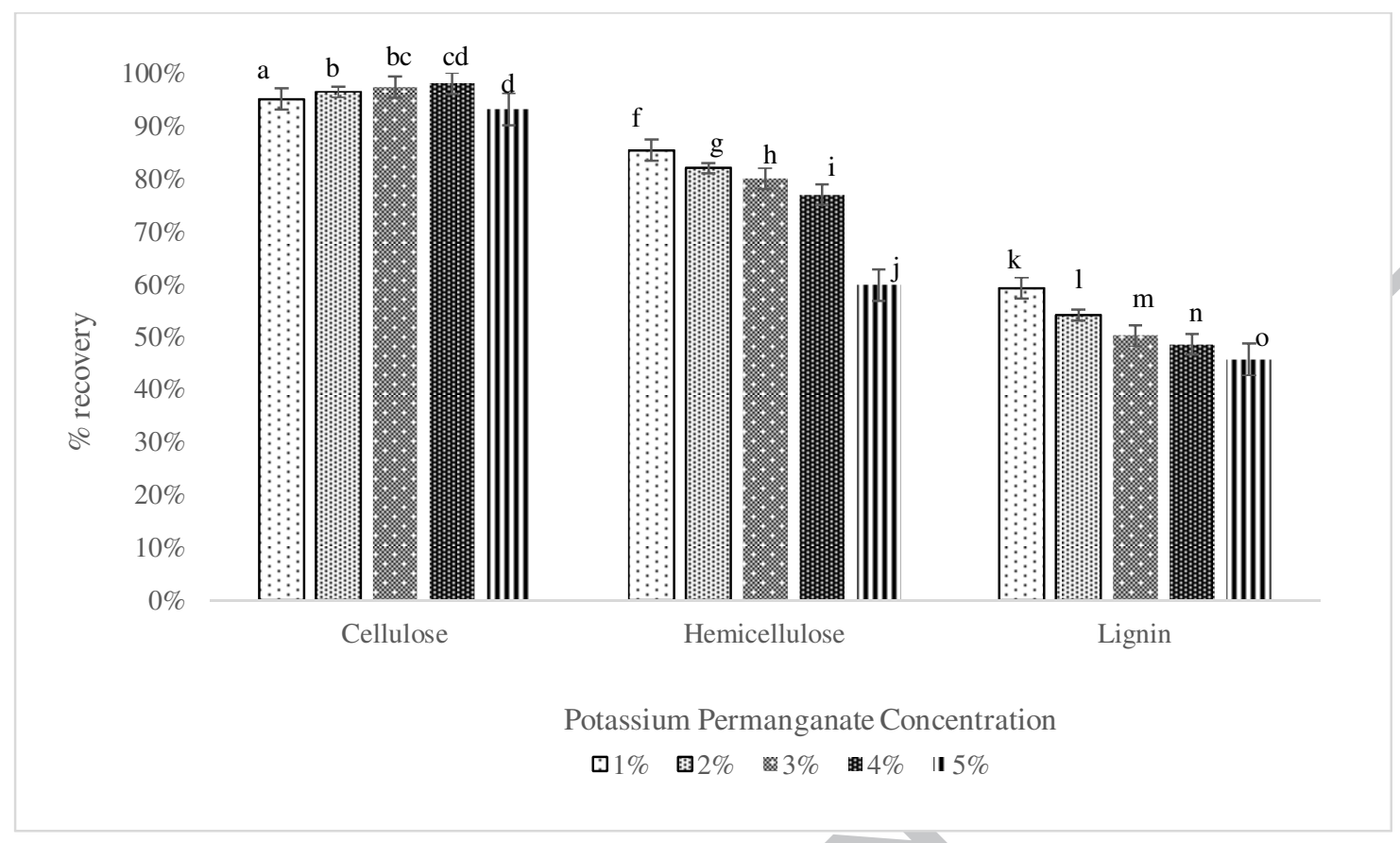

Means not sharing the same letter are significantly different (LSD) at $P<0.05$ probability level for respective lignocellulosic components (cellulose, hemicellulose and lignin).

Fig 1. Effect of potassium permanganate concentration on the recoveries of SCW residues after pretreatment 


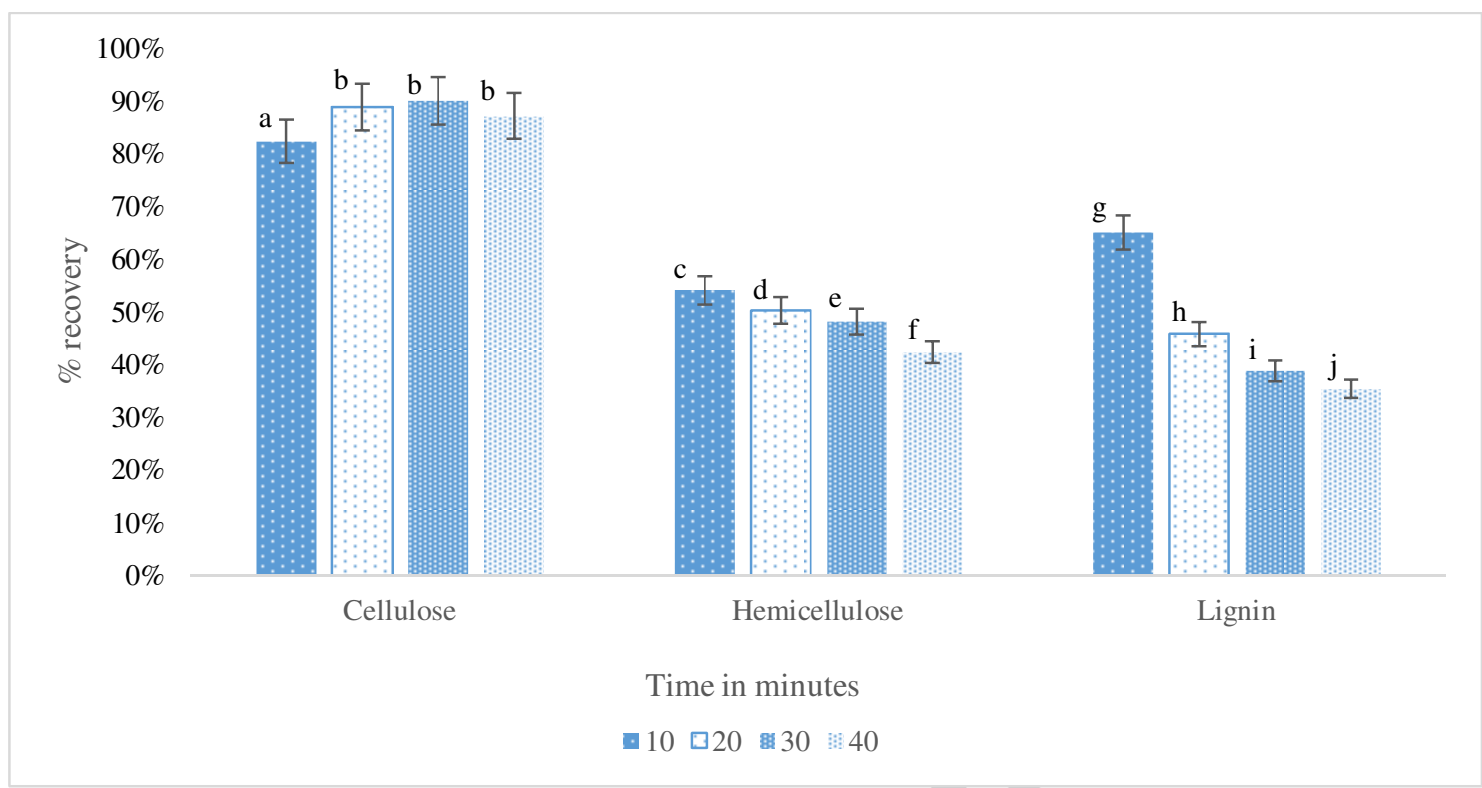

Means not sharing the same letter are significantly different $(L S D)$ at $P<0.05$ probability level for respective lignocellulosic components (cellulose, hemicellulose and lignin).

Fig. 2. Effect of ultrasound exposure on the recoveries of SCW residues after pretreatment 


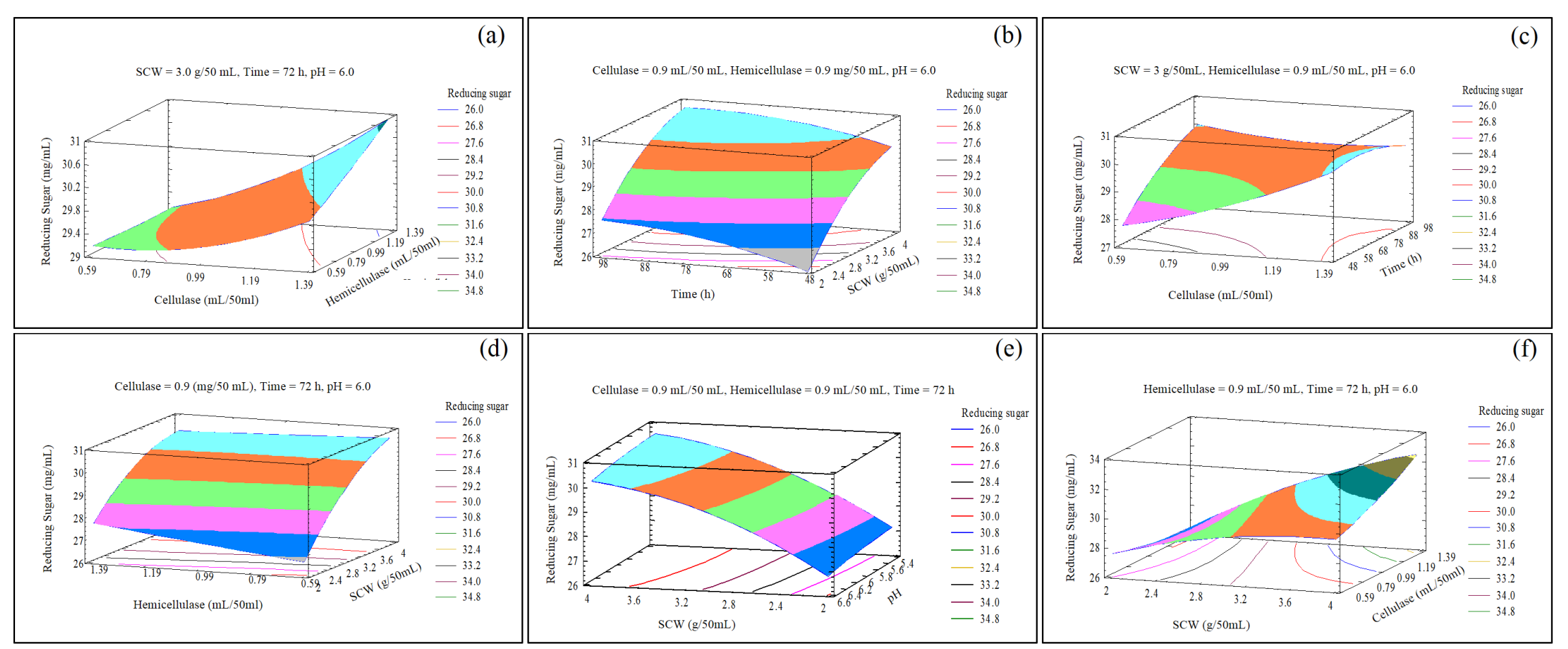

Fig 3. Response surface plots representing the effect of independent variables on reducing sugar yield (3a) the effect of cellulase and hemicellulase on reducing sugar yield when the response surface is fixed at $\mathrm{CSG}=3.0 \mathrm{~g} / 50 \mathrm{~mL}$, time $=72 \mathrm{~h}$ and $\mathrm{pH}=6.0$; $(3 \mathrm{~b})$ representing the effect of time and CSG on reducing sugar yield, when the response surface is fixed at cellulase $=0.9 \mathrm{~mL} / 50 \mathrm{~mL}$, hemicellulase $=0.9 \mathrm{mg} / 50 \mathrm{~mL}$, $\mathrm{pH}=6.0$; (3c) representing the effect of cellulase, time on reducing sugar yield, when the response surface is fixed at $\mathrm{CSG}=3 \mathrm{~g} / 50 \mathrm{~mL}$, hemicellulase $=0.9 \mathrm{~mL} / 50 \mathrm{~mL}, \mathrm{pH}=6.0$; (3d) representing the effect of hemicellulase and CSG on reducing sugar yield, when the response surface is fixed at cellulase $=0.9(\mathrm{mg} / 50 \mathrm{~mL})$, time $=72 \mathrm{~h}, \mathrm{pH}=6.0 ;(3 \mathrm{e})$ representing the effect of $\mathrm{CSG}$ and $\mathrm{pH}$ on reducing sugar yield, when 
the response surface is fixed at cellulase $=0.9 \mathrm{~mL} / 50 \mathrm{~mL}$, hemicellulase $=0.9 \mathrm{~mL} / 50 \mathrm{~mL}$, time $=72 \mathrm{~h}$, and (3f) representing the effect of CSG and cellulase on reducing sugar yield, when the response surface is fixed at hemicellulase $=0.9 \mathrm{~mL} / 50 \mathrm{~mL}$, time $=72 \mathrm{~h}, \mathrm{pH}=6.0$. 


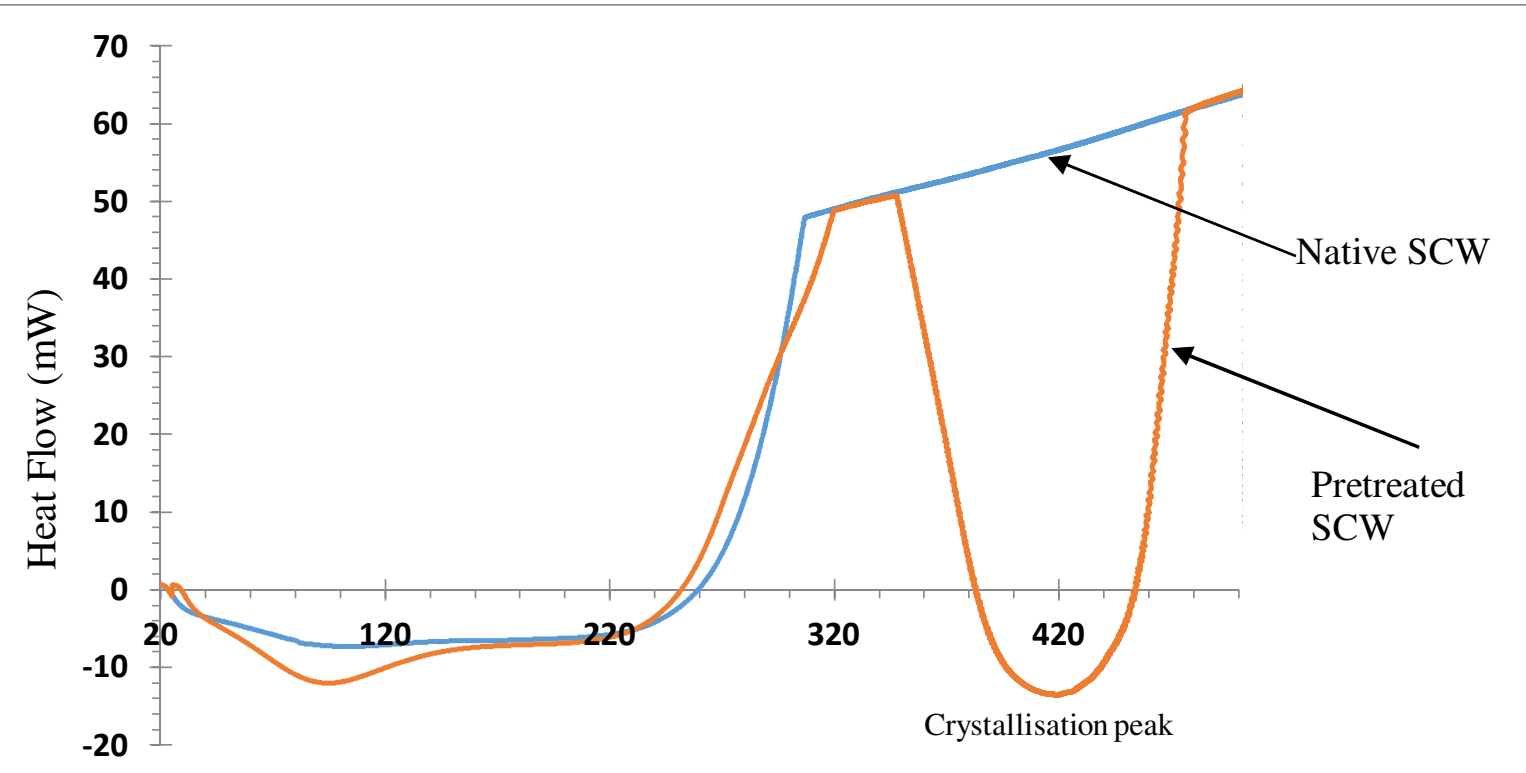

Temperature $\left({ }^{\circ} \mathrm{C}\right)$

Fig. 4. DSC thermogram of native and pretreated SCW. 
5 Table 1. Process variables and level in CCD

\section{Coded}

Independent variables

symbols

Levels

\begin{tabular}{lcccccc}
\cline { 3 - 6 } & & -2 & -1 & 0 & +1 & +2 \\
\hline Biomass loading $(\mathrm{g} / 50 \mathrm{ml})$ & $X_{1}$ & 1 & 2 & 3 & 4 & 5 \\
Cellulase loading (ml/50ml) & $X_{2}$ & 0.3 & 0.6 & 0.9 & 1.2 & 1.5 \\
Hemicellulase loading (ml/50ml) & $X_{3}$ & 0.3 & 0.6 & 0.9 & 1.2 & 1.5 \\
$\mathrm{pH}$ & $X_{4}$ & 4.8 & 5.4 & 6.0 & 6.6 & 7.2 \\
Incubation time (h) & $X_{5}$ & 24 & 48 & 72 & 96 & 120 \\
\hline
\end{tabular}


Table 2. CCD experimental designs for five independent variables, experimental and

8 predicted values for total reducing sugar

\begin{tabular}{|c|c|c|c|c|c|c|}
\hline $\begin{array}{c}\text { Biomass } \\
\text { loading } \\
\text { (g/50ml) } \\
X_{I}\end{array}$ & $\begin{array}{c}\text { Cellulase } \\
\text { loading } \\
\text { (ml/50ml) } \\
X_{2}\end{array}$ & $\begin{array}{c}\text { Hemicellulase } \\
\text { loading } \\
(\mathrm{ml} / 50 \mathrm{ml}) \\
X_{3}\end{array}$ & $\begin{array}{l}\mathrm{pH} \\
X_{4}\end{array}$ & $\begin{array}{c}\text { Incubation } \\
\text { Time (h) } \\
X_{5}\end{array}$ & $\begin{array}{c}\text { Experimental } \\
\text { total } \\
\text { reducing } \\
\text { sugar } \\
(\mathrm{mg} / \mathrm{mL})\end{array}$ & $\begin{array}{c}\text { Predicted } \\
\text { total } \\
\text { reducing } \\
\text { sugar } \\
(\mathrm{mg} / \mathrm{mL})\end{array}$ \\
\hline 2.0 & 1.2 & 1.2 & 6.6 & 48 & 26.5 & 26.5 \\
\hline 2.0 & 0.6 & 0.6 & 5.4 & 96 & 28.5 & 28.4 \\
\hline 2.0 & 0.6 & 1.2 & 6.6 & 96 & 28.5 & 28.5 \\
\hline 3.0 & 0.9 & 1.5 & 6.0 & 72 & 30.1 & 29.7 \\
\hline 3.0 & 0.9 & 0.9 & 6.0 & 24 & 27.1 & 27.0 \\
\hline 2.0 & 0.6 & 1.2 & 5.4 & 48 & 26.1 & 26.1 \\
\hline 4.0 & 1.2 & 0.6 & 5.4 & 96 & 31.5 & 31.5 \\
\hline 3.0 & 0.9 & 0.3 & 6.0 & 72 & 29.6 & 29.4 \\
\hline 3.0 & 0.9 & 0.9 & 6.0 & 72 & 28.9 & 29.1 \\
\hline 5.0 & 0.9 & 0.9 & 6.0 & 72 & 30.8 & 30.4 \\
\hline 2.0 & 1.2 & 0.6 & 6.6 & 96 & 25.7 & 25.6 \\
\hline 4.0 & 0.6 & 0.6 & 6.6 & 96 & 29.8 & 29.9 \\
\hline 4.0 & 1.2 & 1.2 & 5.4 & 48 & 31.5 & 31.5 \\
\hline 3.0 & 0.9 & 0.9 & 6.0 & 72 & 29.2 & 29.4 \\
\hline 4.0 & 1.2 & 1.2 & 5.4 & 48 & 31.0 & 31.1 \\
\hline 3.0 & 1.5 & 0.9 & 6.0 & 72 & 30.6 & 30.6 \\
\hline 3.0 & 0.9 & 0.9 & 7.2 & 72 & 28.9 & 28.7 \\
\hline 2.0 & 0.6 & 0.6 & 6.6 & 48 & 26.0 & 25.9 \\
\hline 3.0 & 0.9 & 0.9 & 4.8 & 72 & 29.5 & 29.5 \\
\hline 3.0 & 0.9 & 0.9 & 6.0 & 72 & 29.2 & 29.4 \\
\hline 3.0 & 0.9 & 0.9 & 6.0 & 72 & 29.2 & 29.4 \\
\hline 2.0 & 1.2 & 0.6 & 5.4 & 48 & 26.0 & 25.9 \\
\hline 2.0 & 1.2 & 1.2 & 6.0 & 96 & 27.8 & 27.9 \\
\hline 1.0 & 0.9 & 0.9 & 6.0 & 72 & 23.3 & 23.6 \\
\hline 4.0 & 0.6 & 0.6 & 5.4 & 48 & 28.7 & 28.8 \\
\hline 4.0 & 0.6 & 1.2 & 5.4 & 96 & 30.3 & 30.5 \\
\hline 4.0 & 0.6 & 1.2 & 5.4 & 96 & 31.1 & 31.3 \\
\hline 4.0 & 0.6 & 1.2 & 6.6 & 48 & 27.6 & 27.8 \\
\hline 3.0 & 0.3 & 0.9 & 6.0 & 72 & 29.4 & 29.2 \\
\hline 3.0 & 0.9 & 0.9 & 6.0 & 120 & 29.7 & 29.5 \\
\hline
\end{tabular}


17 Table 3: Reducing sugar yield and yields of individual monosaccharides in the hydrolysate 18 of SCW after different pretreatments

\begin{tabular}{|c|c|c|c|c|c|c|c|c|}
\hline Pretreatment & Glucose & Arabinose & Galactose & Mannose & Cellobiose & $\begin{array}{c}\text { Acid } \\
\text { Insoluble } \\
\text { Lignin }\end{array}$ & $\begin{array}{c}\text { Acid } \\
\text { soluble } \\
\text { lignin }\end{array}$ & $\begin{array}{c}\text { Total } \\
\text { Reducing } \\
\text { Sugar }\end{array}$ \\
\hline Raw & $25.1 \pm 0.3$ & $21.3 \pm 1.2$ & $13.5 \pm 0.9$ & $10.5 \pm 0.8$ & $4.1 \pm 1.3$ & $27.21 \pm 0.4$ & $3.89 \pm 0.3$ & $199.8 \pm 1.8$ \\
\hline $\begin{array}{l}\mathrm{NaOH}+ \\
\text { Ultrasonication }\end{array}$ & $51.1 \pm 0.4$ & $35.1 \pm 1.7$ & $23.3 \pm 1.3$ & $12.4 \pm 0.2$ & $2.3 \pm 0$. & $20.89 \pm 1.3$ & $5.15 \pm 0.6$ & $305.6 \pm 2.3$ \\
\hline $\begin{array}{l}\mathrm{KmNO}_{4} \\
\text { +Ultrasonication }\end{array}$ & $62.4 \pm 0.6$ & $45.6 \pm 0.1$ & $33.7 \pm 1.5$ & $16.01 \pm 0.3$ & $7.7 \pm 0.8$ & $16.02 \pm 0.7$ & $6.2 \pm 1.6$ & $341.2 \pm 1.2$ \\
\hline
\end{tabular}

19 Glucose, arabinose, galactose, mannose, and cellobiose results are presented as $\mathrm{mg} / \mathrm{g}$ of dry SCW; acid insoluble lignin and acid

20 soluble lignin results are presented as $\mathrm{g} / 100 \mathrm{~g}$ of dry SCW, while reducing sugar result is presented as $\mathrm{mg} / \mathrm{g}$ of SCW.

21

22

23

24

25 
27 - A novel one-step pretreatment for spent coffee waste has been presented in this study.

28 - Extensive delignification in coffee was achieved using ultrasound-assisted potassium 29 permanganate pretreatment.

30 - The polysaccharide fraction of spent coffee waste was left unaffected.

31 - Pretreatment leads to high reducing sugar yield upon enzymatic hydrolysis of spent 32 coffee waste.

33

34 